\title{
Review Article \\ Sodium Hypochlorite Irrigation and Its Effect on Bond Strength to Dentin
}

\author{
Tariq S. Abuhaimed ${ }^{1}$ and Ensanya A. Abou Neel ${ }^{1,2,3}$ \\ ${ }^{1}$ Division of Biomaterials, Operative Dentistry Department, King Abdulaziz University, Jeddah, Saudi Arabia \\ ${ }^{2}$ Biomaterials Department, Faculty of Dentistry, Tanta University, Tanta, Egypt \\ ${ }^{3}$ Biomaterials and Tissue Engineering Division, Eastman Dental Institute, UCL, 256 Gray's Inn Road, London WC1X 8LD, UK \\ Correspondence should be addressed to Ensanya A. Abou Neel; eabouneel@kau.edu.sa
}

Received 14 May 2017; Revised 28 June 2017; Accepted 12 July 2017; Published 20 August 2017

Academic Editor: Nick Silikas

Copyright (C) 2017 Tariq S. Abuhaimed and Ensanya A. Abou Neel. This is an open access article distributed under the Creative Commons Attribution License, which permits unrestricted use, distribution, and reproduction in any medium, provided the original work is properly cited.

\begin{abstract}
Effective shaping and cleaning of root canals are essential for the success of endodontic treatment. Due to the complex anatomy of root canal spaces, the use of various instrumentation techniques alone is not effective in producing bacteria-free root canal spaces. Irrigation, disinfectants, rinses, and intervisit medications are used in conjunction with the mechanical instrumentation to ensure the success of endodontic treatment. Sodium hypochlorite $(\mathrm{NaOCl})$, a halogenated compound, is routinely used to irrigate the root canal during endodontic treatments. $\mathrm{NaOCl}$ has been known for its antibacterial action, proteolytic and dissolution capacity, and debridement properties. $\mathrm{NaOCl}$, however, can alter the composition of dentin and hence its interaction with the adhesive resins used to bond the restorative materials to treated dentin. This review therefore covers in depth the action of $\mathrm{NaOCl}$ on dentinadhesive resin bond strength including both enhancement and reduction, then mechanisms proposed for such action, and finally how the adverse action of $\mathrm{NaOCl}$ on dentin can be reversed.
\end{abstract}

\section{Introduction}

Effective shaping and cleaning of root canals are essential for the success of endodontic treatments. Due to the complex anatomy of root canal spaces, the use of various instrumentation techniques alone is not effective in producing bacteriafree root canal spaces $[1,2]$. Large areas of root canal dentin could remain untouched by the instruments; this emphasizes the importance of chemical means of cleaning and disinfecting the root canal system [2]. Various chemicals, for example, irrigations, disinfectants, rinses, and intervisit medications are used in conjunction with the mechanical instrumentation to ensure the success of endodontic treatments $[1,3]$. Irrigation flushes away all loose, necrotic, or contaminated tissues and materials from the root canal before being pushed into the apical tissues. It also provides lubrication, debridement, destruction of microbes, and dissolution of tissues [4].

Sodium hypochlorite $(\mathrm{NaOCl})$, a halogenated compound, is routinely used to irrigate the root canal during endodontic treatments. It has antimicrobial action [5-8]; in water, sodium hypochlorite ionizes to $\mathrm{Na}$ and $\mathrm{OCl}$. Between $\mathrm{pH}$ values 4 and 7 , chlorine ion exists as hypochlorous acid ( $\mathrm{HClO}$ ) while, at $\mathrm{pH}$ above $9, \mathrm{OCl}$ predominates. $\mathrm{HClO}$ has a strong antibacterial action compared to $\mathrm{OCl}$ due to its ability to disrupt the oxidative phosphorylation and other membrane-associated activities [9]. $\mathrm{HClO}$ also exerts a rapid inhibitory effect on mitochondrial function and DNA synthesis of bacteria [10]. In addition to its antibacterial action, sodium hypochlorite has the ability to dissolve the pulpal remnants [11, 12] and organic component of dentin (i.e., nonspecific proteolytic action [3]). It also has the ability to partially neutralize the necrotic tissues or any antigenic or microbial component left in the root canal space [13] and remove all pulpal remnants and predentin on the uninstrumented surfaces [14]. The tissue dissolution capacity and debridement properties can be significantly improved by increasing the temperature and concentration of sodium hypochlorite $[15,16]$. The penetration ability to the uninstrumented area of root canal systems can be increased by lowering the surface tension of $\mathrm{NaOCl}$ [17]. Regardless of its 
significant effect on the organic component of dentin, $\mathrm{NaOCl}$ has no effect on dentin's inorganic part [18].

Chemicals used during the preparation of root canals, however, can alter the composition and hence the interaction of dentin surface with the restorative materials. In literatures, there are conflicting results on how the treatment of dentin with $\mathrm{NaOCl}$ affects the subsequent bond strength. Such variation in response to sodium hypochlorite could be related to the variation in methodology, form (gel versus liquid) and concentration of sodium hypochlorite, time of application [19], and many other factors that will be discussed in detail in this review.

\section{Effect of Sodium Hypochlorite on Dentin Bonding}

Wakabayashi et al. observed that the treatment of dentin with $10 \% \mathrm{NaOCl}$ after etching with $40 \%$ phosphoric acid enhanced the tensile strength of adhesive to dentin. Even after thermocycling $\left(10,000\right.$ cycles at $\left.4-60^{\circ} \mathrm{C}\right)$, the bond strength was 1.5 times higher than that recorded for etched dentin [20]. Vagas et al. observed that a 2-minute exposure of dentin to $5 \% \mathrm{NaOCl}$ following acid etching improved the shear bond strength for All-Bond 2 but had no significant effect on Scotchbond Multi-Purpose [21]. Prati et al. observed that treatment of etched (35\% phosphoric acid for $20 \mathrm{~s}$ ) dentin with $\mathrm{NaOCl}(1.5 \%$ for $2 \mathrm{~min}$ or $10 \%$ for $120 \mathrm{hr}$ ) improved the shear bond strength of Optibond FL when compared to etched dentin. The bond strength of Scotchbond MP and $3 \mathrm{M}$ Single Bond to etched/NaOCl-treated dentin was significantly reduced when compared to etched dentin. The bond strength of Prime \& Bond 2.0, however, remained unmodified compared to etched dentin. Long term $(120 \mathrm{hr})$ $\mathrm{NaOCl}$ treatment of etched dentin produced an exceptional layer of resin-infiltrated mineralized dentin "reverse hybrid layer"; this will be discussed later in this review [22]. Ari et al. observed that the microtensile bond strength to 5\% $\mathrm{NaOCl}$-treated dentin has been significantly improved with C\&B Metabond compared to with Panavia F and Variolink II [23].

Stevens observed that the pretreatment of dentin with $6 \%$ $\mathrm{NaOCl}$ (20 min exposure) adversely affects the bond strength of self-etching, self-adhesive resin cements (Speed CEM and Clearfil SA Cement) but not total-etch (Variolink II) adhesives and those with a separate bonding agent (Multilink and Clearfil Esthetic Cement EX) [24]. Similar findings were also observed by Ishizuka et al., who observed that the bond strength of self-etching primer systems (Clearfil Mega Bond) significantly decreased after being applied to $6 \% \mathrm{NaOCl}$ treated dentin (1 or 5 or 10 min exposure) while that of totaletch system (Single Bond) did not change [25]. Contradicting results were observed in other studies. Frankenberger et al. observed a significant reduction in dentin push-out bond strength with both total-etch (Scotchbond Multi-Purpose Plus, EBS, and Solid Bond) and self-etch (Prime \& Bond 2.1, Syntac Sprint) adhesives with dentin [26]. Nikaido et al. observed a significant reduction in bond strength only with total-etch (Single Bond II) and Superbond C\&B [a selfcure resin cement based on 4-methacryloxyethyl trimellitate anhydride in methyl methacrylate initiated by tri-n-butyl borane (4-META/MMA-TBB)], but the bond strength of self-etching primer system (Clearfil Mega Bond) did not significantly change when applied to $5 \% \mathrm{NaOCl}$-treated dentin (60 s exposure) [27]. Vongphan et al. observed a significant reduction in bond strength of total-etch system (Single Bond) when bonded to $5.25 \% \mathrm{NaOCl}$-treated dentin (10 min exposure) [28]. Perdigão et al. observed that the shear bond strength of two total-etch adhesives (Prime \& Bond NT and Single Bond) has been significantly reduced with the application of $10 \% \mathrm{NaOCl}$ gel on dentin [29]. This reduction was significantly increased with increasing the time of gel application [29]. Morris et al. observed a significant reduction in the tensile bond strength of Metabond resin cements to 5\% NaOCl-treated dentin (15-20 min exposure) [30]. Soeno et al. observed a significant reduction in bond strength of a carboxylic (4-META/MMA-TBB) resin to $10 \mathrm{wt} \% \mathrm{NaOCl}$ treated dentin (30 s exposure) [31]. A summary of these studies is presented in Table 1.

As observed the effect of sodium hypochlorite on dentin bonding varies with chemistries of the bonding systems[32]. Such variation in bonding systems' chemistries was related to the ability of their etchants to remove the degenerated dentin, produced by acid etching, as well as the residual $\mathrm{NaOCl}$, that would interfere with the free radical polymerization reaction of resin cement, from treated dentin [25]. As suggested by some authors, single bond etchants, for example, have the ability to remove the degenerated dentin and residual $\mathrm{NaOCl}$ from treated dentin but not the self-etching primer of Mega Bond. According to this suggestion, the bond strength with $\mathrm{NaOCl}$-treated dentin has been improved with single bond adhesives compared to self-etch systems [25]. This assumption can only explain the enhancement but not the reduction of bond strength seen with single bond adhesives. Therefore other factors could play a key part in bond strength to $\mathrm{NaOCl}$-treated dentin, for instance, the form (solution or gel), concentration, and time of application of sodium hypochlorite [19]. Regardless of the variation in bonding systems and testing methods used, like $6 \%$ sodium hypochlorite [24], 5\% (for 15-20 min) produced a significant reduction in the tensile resin-dentin bond strength of Metabond resin cements as discussed above [30]. However, when the time of $\mathrm{NaOCl}$ application has been reduced, in another study, to $60 \mathrm{~s}$, still a significant reduction in bond strength was achieved with 5\% $\mathrm{NaOCl}$ [33]. Also $2.5 \% \mathrm{NaOCl}$ applied for $60 \mathrm{~s}$ significantly reduced the pull-out bond strength of dentin to self-adhesive resin cements [34]. On the other hand, using $1 \% \mathrm{NaOCl}$ ( $5 \mathrm{ml}$ applied every $5 \mathrm{~min}$ for $1 \mathrm{hr}$ ) significantly improved the tensile bond strength of dentin [35]. In these studies [30, 3335], however as highlighted above, the concentration and time of $\mathrm{NaOCl}$ application were not the only variables to be considered responsible for the action of $\mathrm{NaOCl}$. Therefore, the source of dentin samples (animal or human), as well as the age of human or animal from which the samples were collected, is another factor to be considered. The storage condition of dentin samples, the regional variation (coronal versus root dentin/cervical versus middle versus apical root canal dentin) [30], and location (superficial versus root canal wall) of dentin $[25,36]$ would also play a part. Variation in technique used 


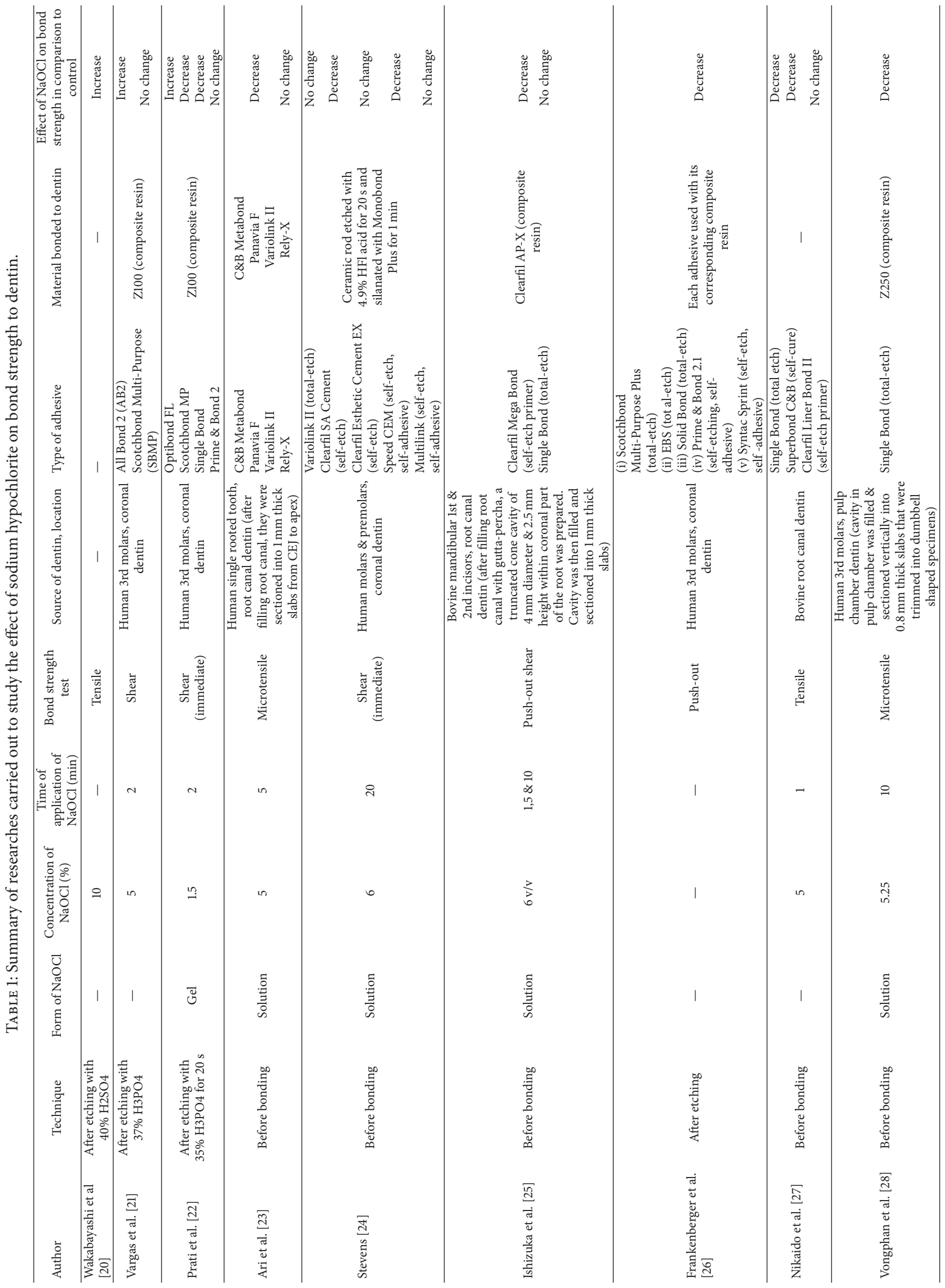




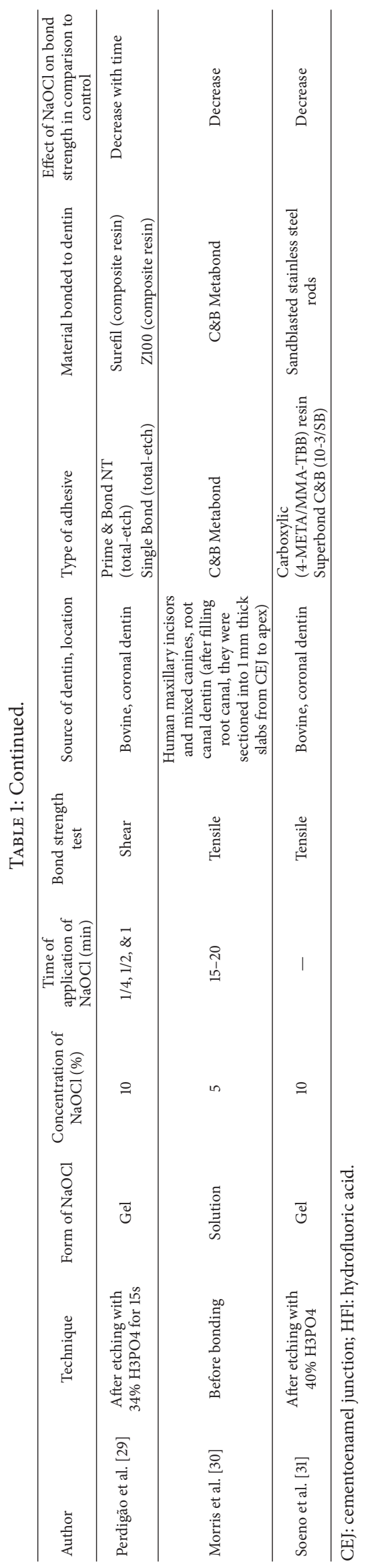


to prepare samples and to measure the bond strength (shear, tensile, push-out or pull-out, etc.) could be another factor.

Regardless of the wide variation in results, only few studies reported an enhancement in resin bond strength after dentin treatment with sodium hypochlorite. The proposed mechanisms for either enhancement or reduction in dentin bond strength will be discussed in the next section.

\section{Suggested Mechanisms for the Action of Sodium Hypochlorite on Dentin Bond Strength}

3.1. Bond Strength Enhancement. Regarding the action of sodium hypochlorite itself, the enhancement in dentin bond strength observed after $\mathrm{NaOCl}$ treatment has been related to its deproteinizing action. $\mathrm{NaOCl}$ has the ability to dissolve and remove the exposed dentinal collagen, produced by acid etching, and provide a fresh mineralized dentin surface to which the adhesive resin can be applied. This allows a direct adhesion between the adhesive resin and dentin without the resin-reinforced collagen layer, called hybrid layer [20, 21]. According to Prati et al., $\mathrm{NaOCl}$ produced an unusual new mechanism of micromechanical retention of resin into mineralized dentin, called "reverse hybrid layer formation" [22]. For the formation of conventional hybrid layer, the technique relies on the use of acid etching to remove the smear layer as well as the mineral phase of dentin (i.e., exposing collagen fibrils). Upon subsequent use of the adhesive resin, the resin infiltrates around the exposed collagen fibrils and replaces the lost mineral phase (i.e., creating a layer of "resininfiltrated collagen"). The application of $\mathrm{NaOCl}$ after acid etching and before the adhesive resin does not only remove the exposed collagen, produced by acid etching, but also solubilize the fibrils of the underlying mineralized matrix creating submicron porosities within the mineral phase. The adhesive resin will therefore infiltrate within the mineralized matrix filling these submicron porosities (i.e., creating a layer of resin-infiltrated mineralized matrix) [22]. Furthermore, the removal of exposed collagen does not only reduce the bonding technique sensitivity but also produce a more porous surface (i.e., an increase in size of dentinal tubules with the presence of an extensive labyrinth of lateral tubules that open on intertubular and/or peritubular dentin) [37] and larger resin tags [22] that would produce interfaces with high bond strength. The use of $\mathrm{NaOCl}$ also produced an acid-base resistant zone under the hybrid layer; this zone could help in resisting secondary caries around restorations [38].

3.2. Bond Strength Reduction. On the other hand, several mechanisms have been suggested for the adverse effect of $\mathrm{NaOCl}$ on dentin bond strength. It has been postulated that the reduction in bond strength after sodium hypochlorite treatment could be attributed to the removal of organic matrix from the treated dentin, leaving a less receptive bonding surface [39]. Furthermore, the removal of the organic matrix of dentin (i.e., dissolution of collagen fibrils from dentin by breakdown of the bonds between carbon atoms and disorganization of the primary structure of collagen) impedes the formation of a consistent hybrid layer [27]. After fragmentation of long collagen chains, it also chlorinates the protein terminal groups that are further broken down into smaller units [40]. The presence of protein chloraminederived radicals in $\mathrm{NaOCl}$-treated dentin could result in premature chain termination and hence incomplete polymerization of adhesive resins [41]. This means that sodium hypochlorite acts as an oxidizing agent and accordingly interferes with the free radical polymerization of the resin cement at the resin-dentin interface [42]. Another possible cause for the reduction in bond strength has been attributed to the presence of residual irrigants and/or their products that can easily diffuse into the dentin via dentinal tubules. These residual chemicals may contaminate the dentin surface and interfere with the penetration of resin adhesive into the dentin or the polymerization of resin monomer [27]. Even with complete penetration of resin adhesive into treated dentin, the bond strength is still reduced. This emphasizes the importance of the integrity of collagen fibrils left after acid etching and the quality of the hybrid layer (intermingling of adhesive resin with collagen fibrils) in dentin bonding [29]. Furthermore, the reduction in both calcium and phosphorus ions in dentin [43] and hence a reduction in dentin strength and elasticity $[44,45]$ could be responsible for the reduction in bond strength. The deterioration effect of sodium hypochlorite on structural, chemical, and mechanical properties of dentin is concentration-dependent. For example, $1 \% \mathrm{NaOCl}$ had no significant adverse effect on carbon and nitrogen content as well as elasticity and flexural strength of dentin in contrast to 5 and $9 \%$ [45].

\section{Reversing the Adverse Action of Sodium Hypochlorite on Dentin Bond Strength}

The negative action of $\mathrm{NaOCl}$ on dentin bond strength can be reversed by some natural antioxidants, for example, ascorbic acid [30], sodium ascorbate [30,39, 46], rosmarinic acid [46], green tea extracts [47], and proanthocyanidin [48]. These antioxidants could improve the bond strength to $\mathrm{NaOCl}-$ treated dentin and stabilize the resin-dentin interface due to their antioxidative capacities. They also remove the remnant of sodium hypochlorite by oxidation-reduction reaction. They have been therefore introduced as polymerizationfacilitating agents and cross-linkers [46].

4.1. Ascorbic Acid and Sodium Ascorbate. L-ascorbic acid is water-soluble vitamin C; sodium ascorbate is a salt of ascorbic acid. Both are known for their antioxidant action. Stevens 2014 observed that a rinse with $10 \%$ sodium ascorbate (for 5 and $60 \mathrm{~s}$ ) after $\mathrm{NaOCl}$ provided an immediate restoration of at least $50 \%$ of the original bond strength with the susceptible resin cements (self-etching, self-adhesive) [24]. The application of $10 \%$ sodium ascorbate for $10 \mathrm{~min}$ on $\mathrm{NaOCl}$-treated dentin enhanced the bond strength of the total-etch system [28]. 10\% sodium ascorbate also improved the degree of conversion and bond strength of RealSeal to $\mathrm{NaOCl}$-treated dentin [49]. The reduction in bond strength of Metabond resin cements was also reversed by the application of either $10 \%$ sodium ascorbate (from 1-10 min) $[30,39,46]$ or 
$10 \%$ ascorbic acid [30]. With the 4-META/MMA-TBB resin, $10 \mathrm{wt} \%$ ascorbic acid or $5 \mathrm{wt} \%$ sodium thiosulfate solution is used to reverse the action of sodium hypochlorite [31].

The action of sodium ascorbate was more effective in improving the bond strength than ascorbic acid [30]. Unlike ascorbic acid, sodium ascorbate has reducing action on root dentin and hence does not interfere with the polymerization of methyl methacrylate in resin cements used to fill the root canal [30]. It has been also suggested that sodium ascorbate can promote the polymerization reaction of adhesive resin without premature termination caused by $\mathrm{NaOCl}$ and reverses the disrupted bonding to $\mathrm{NaOCl}$-treated dentin [50].

4.2. Rosmarinic Acid. Rosmarinic acid is a polyphenolic compound that can be extracted from the rosemary plant; it is a potent antioxidizing agent $[51,52]$ and matrix metalloproteinases (MMP, involved in the degradation process of hybrid layer) inhibitor [53]. The application of $100 \mu \mathrm{M}$ rosmarinic acid solution for 5 or $10 \mathrm{~s}$ improved the microtensile bond strengths to $6 \% \mathrm{NaOCl}$-treated dentin (30 s exposure); in this study, however, $10 \%$ sodium ascorbate solution was not effective in reversing the reduced pull-out bond strength [46]. In another study, $10 \%$ rosmarinic acid applied for $2 \mathrm{~min}$ was effective in reversing the reduced action of $\mathrm{NaOCl}$ on dentin and $10 \%$ sodium ascorbate hydrogel for $2 \mathrm{~min}$ was more effective than rosmarinic acid [34].

4.3. Green Tea Extract. Green tea extract is made from Camellia sinensis; it is composed of polyphenols, called catechins, as epicatechin, epicatechin gallate, epigallocatechin, and epigallocatechin gallate. Both epicatechin gallate and epigallocatechin gallate are characterized by their MMP inhibition action [54]. It also has antibacterial action; therefore, it has been proposed as root canal irrigant $[55,56]$. Therefore, in addition to its antioxidant action, the application of $20 \mu \mathrm{l}$ of $2 \%$ green tea extract for $60 \mathrm{~s}$ was effective in increasing the bond durability of etch and rinse system to dentin [57].

4.4. Proanthocyanidin (Grape Seed Extract). Proanthocyanidin has been found in high concentration in grape seed extract, pin bark extract, cocoa beans, lemon tree bark, and hazel nut tree leaves [48]. It has been observed that the antioxidant ability of proanthocyanidin is 20 times higher than that reported for sodium ascorbate; its absorbtion can be quicker and more complete than sodium hypochlorite [58]. The action of $5 \%$ proanthocyanidin is more effective than $10 \%$ sodium ascorbate in reversing the action of sodium hypochlorite [48]. Gallic acid, observed in proanthocyanidin, could play an important role in enhancing the bond strength. Finally, the ability of proanthocyanidin to cross-link and hence stabilize collagen could also increase the bond strength. All these factors could contribute to the strong reversal action of proanthocyanidin on the negative action of sodium hypochlorite [48].

It has been observed that proanthocyanidin enhanced the bond strength and durability of resin based sealers to root canal dentin after short storage in water; it also improved the resistance of demineralized dentin to degradation [59]. The inclusion of proanthocyanidin into dental adhesives, however, reduced the bond strength particularly when incorporated at high concentration (3\%) [60]. Furthermore, the incorporation of proanthocyanidin into the adhesive produced a significant effect in reducing the bond strength compared to when it is incorporated into the primer [61].

\section{Concluding Remarks}

Under the light of this review, standardization of dentin source, preparation techniques, and testing methods is critical for assessing the action of $\mathrm{NaOCl}$ on dentin. Furthermore, simulating as much as possible the clinical scenario during which the material is used is another factor to be considered in conducting any relevant study. Clinically, $\mathrm{NaOCl}$ is used to irrigate the root canal system (i.e., confined environment), but in most in vitro studies, covered in this review, it is applied to flat dentin discs (i.e., unconfined environment). The penetration of $\mathrm{NaOCl}$ and hence its effect on dentin in both cases will be different. Additionally, $\mathrm{NaOCl}$ has been constantly applied for $10-20 \mathrm{~min}$ or even longer periods (hours in some studies) and this could not be achieved in clinical scenarios. Therefore, it would be expected that the action of $\mathrm{NaOCl}$ in these studies would be more aggressive than what happens in reality.

Regardless of the conflict seen in literature about the action of sodium hypochlorite on dentin bond strength, some natural antioxidants, for example, ascorbic acid, sodium ascorbate, rosmarinic acid, green tea extracts, and proanthocyanidin, could be very effective in modifying dentin surface and hence affecting its bond strength to other materials. In addition to their antioxidant action, some of these natural antioxidants have antibacterial action (e.g., green tea extracts) or work as matrix metalloproteinases inhibitors (e.g., rosmarinic acid). Therefore they could also increase the resistance of dentin to biodegradation and hence stabilize the resin adhesive-dentin interface by attacking any residual bacteria or inhibiting the degradation of the hybrid layer.

\section{Conflicts of Interest}

The authors declare that there are no conflicts of interest regarding the publication of this paper.

\section{References}

[1] M. Haapasalo, U. Endal, H. Zandi, and J. M. Coil, "Eradication of endodontic infection by instrumentation and irrigation solutions," Endodontic Topics, vol. 10, no. 1, pp. 77-102, 2005.

[2] O. A. Peters, K. Schönenberger, and A. Laib, "Effects of four $\mathrm{Ni}$-Ti preparation techniques on root canal geometry assessed by micro computed tomography," International Endodontic Journal, vol. 34, no. 3, pp. 221-230, 2001.

[3] Z. Mohammadi, "Sodium hypochlorite in endodontics: An update review," International Dental Journal, vol. 58, no. 6, pp. 329-341, 2008.

[4] M. Haapasalo, Y. Shen, W. Qian, and Y. Gao, "Irrigation in endodontics," Dental Clinics of North America, vol. 54, no. 2, pp. 291-312, 2010.

[5] J. F. Siqueira Jr., A. G. Machado, R. M. Silveira, H. P. Lopes, and M. De Uzeda, "Evaluation of the effectiveness of sodium 
hypochlorite used with three irrigation methods in the elimination of Enterococcus faecalis from the root canal, in vitro," International Endodontic Journal, vol. 30, no. 4, pp. 279-282, 1997.

[6] B. Retamozo, S. Shabahang, N. Johnson, R. M. Aprecio, and M. Torabinejad, "Minimum Contact Time and Concentration of Sodium Hypochlorite Required to Eliminate Enterococcus faecalis," Journal of Endodontics, vol. 36, no. 3, pp. 520-523, 2010.

[7] A. del Carpio-Perochena, C. Monteiro Bramante, M. Hungaro Duarte et al., "Effect of Temperature, Concentration and Contact Time of Sodium Hypochlorite on the Treatment and Revitalization of Oral Biofilms," Journal of Dental Research, Dental Clinics, Dental Prospects, vol. 9, no. 4, pp. 209-215, 2015.

[8] C. E. Radcliffe, L. Potouridou, R. Qureshi et al., "Antimicrobial activity of varying concentrations of sodium hypochlorite on the endodontic microorganisms Actinomyces israelii, A. naeslundii, Candida albicans and Enterococcus faecalis," International Endodontic Journal, vol. 37, no. 7, pp. 438-446, 2004.

[9] J. Marcinkiewicz, B. Chain, B. Nowak, A. Grabowska, K. Bryniarski, and J. Baran, "Antimicrobial and cytotoxic activity of hypochlorous acid: Interactions with taurine and nitrite," Inflammation Research, vol. 49, no. 6, pp. 280-289, 2000.

[10] E. Hidalgo, R. Bartolome, and C. Dominguez, "Cytotoxicity mechanisms of sodium hypochlorite in cultured human dermal fibroblasts and its bactericidal effectiveness," ChemicoBiological Interactions, vol. 139, no. 3, pp. 265-282, 2002.

[11] M. V. R. Sá, F. V. Vier-Pelisser, M. S. Darcie, D. G. R. Smaniotto, F. Montagner, and M. C. Kuga, "Pulp tissue dissolution when the use of sodium hypochlorite and EDTA alone or associated," Revista Odonto Ciencia, vol. 26, no. 2, pp. 156-160, 2011.

[12] S. Taneja, N. Mishra, and S. Malik, "Comparative evaluation of human pulp tissue dissolution by different concentrations of chlorine dioxide, calcium hypochlorite and sodium hypochlorite: An in vitro study," Journal of Conservative Dentistry, vol. 17, no. 6, pp. 541-545, 2014.

[13] M. Andersen, A. Lund, J. O. Andreasen, and F. M. Andreasen, "In vitro solubility of human pulp tissue in calcium hydroxide and sodium hypochlorite," Dental Traumatology, vol. 8, no. 3, pp. 104-108, 1992.

[14] J. Craig Baumgartner and C. L. Mader, "A scanning electron microscopic evaluation of four root canal irrigation regimens," Journal of Endodontics, vol. 13, no. 4, pp. 147-157, 1987.

[15] M. Abou-Rass and S. W. Oglesby, "The effects of temperature, concentration, and tissue type on the solvent ability of sodium hypochlorite," Journal of Endodontics, vol. 7, no. 8, pp. 376-377, 1981.

[16] W. T. Cunningham and A. Y. Balekjian, "Effect of temperature on collagen-dissolving ability of sodium hypochlorite endodontic irrigant," Oral Surgery, Oral Medicine, Oral Pathology, vol. 49, no. 2, pp. 175-177, 1980.

[17] F. Palazzi, M. Morra, Z. Mohammadi, S. Grandini, and L. Giardino, "Comparison of the surface tension of $5.25 \%$ sodium hypochlorite solution with three new sodium hypochloritebased endodontic irrigants," International Endodontic Journal, vol. 45, no. 2, pp. 129-135, 2012.

[18] D. Kandaswamy and N. Venkateshbabu, "Root canal irrigants," Journal of Conservative Dentistry, vol. 13, no. 4, pp. 256-264, 2010.

[19] K. Zhang, Y. K. Kim, M. Cadenaro et al., "Effects of Different Exposure Times and Concentrations of Sodium Hypochlorite/Ethylenediaminetetraacetic Acid on the Structural Integrity of Mineralized Dentin," Journal of Endodontics, vol. 36, no. 1, pp. 105-109, 2010.

[20] Y. Wakabayashi, Y. Kondou, K. Suzuki, H. Yatani, and A. Yamashita, "Effect of dissolution of collagen on adhesion to dentin," International Journal of Prosthodontics, vol. 7, no. 4, pp. 302-306, 1994.

[21] M. A. Vargas, D. S. Cobb, and S. R. Armstrong, "Resin-dentin shear bond strength and interfacial ultrastructure with and without a hybrid layer," Operative Dentistry, vol. 22, no. 4, pp. 159-166, 1997.

[22] C. Prati, S. Chersoni, and D. H. Pashley, "Effect of removal of surface collagen fibrils on resin-dentin bonding," Dental Materials, vol. 15, no. 5, pp. 323-331, 1999.

[23] H. Ari, E. Yaşar, and S. Bellí, "Effects of $\mathrm{NaOCl}$ on bond strengths of resin cements to root canal dentin," Journal of Endodontics, vol. 29, no. 4, pp. 248-251, 2003.

[24] C. D. Stevens, "Immediate shear bond strength of resin cements to sodium hypochlorite-treated dentin," Journal of endodontics, vol. 40, no. 9, pp. 1459-1462, 2014.

[25] T. Ishizuka, H. Kataoka, T. Yoshioka et al., "Effect of $\mathrm{NaClO}$ Treatment on Bonding to Root Canal Dentin Using a New Evaluation Method," Dental Materials Journal, vol. 20, no. 1, pp. 24-33, 2001.

[26] R. Frankenberger, N. Krämer, H. Oberschachtsiek, and A. Petschelt, "Dentin bond strength and marginal adaption after $\mathrm{NaOCl}$ pre-treatment." Operative dentistry, vol. 25, no. 1, pp. 40-45, 2000.

[27] T. Nikaido, Y. Takano, Y. Sasafuchi, M. F. Burrow, and J. Tagami, "Bond strengths to endodontically-treated teeth," American Journal of Dentistry, vol. 12, no. 4, pp. 177-180, 1999.

[28] N. Vongphan, P. Senawongse, W. Somsiri, and C. Harnirattisai, "Effects of sodium ascorbate on microtensile bond strength of total-etching adhesive system to $\mathrm{NaOCl}$ treated dentine," Journal of Dentistry, vol. 33, no. 8, pp. 689-695, 2005.

[29] J. Perdigão, M. Lopes, S. Geraldeli, G. C. Lopes, and F. GarcíaGodoy, "Effect of a sodium hypochlorite gel on dentin bonding," Dental Materials, vol. 16, no. 5, pp. 311-323, 2000.

[30] M. D. Morris, K. W. Lee, KA. Agee, S. Bouillaguet, and D. H. Pashley, "Effects of sodium hypochlorite and RC-prep on bond strengths of resin cement to endodontic surfaces," Journal of Endodontics, vol. 27, no. 12, pp. 753-757, 2001.

[31] K. Soeno, Y. Taira, H. Matsumura, M. Atsuta, and S. Suzuki, "Adhesion of 4-META/MMA-TBB resin to collagen-depleted dentin - Effect of conditioner with ascorbic acid/ferric chloride," Dental Materials Journal, vol. 23, no. 2, pp. 100-105, 2004.

[32] T. Pioch, S. Kobaslija, B. Schagen, H. G, and H. Götz, "Interfacial micromorphology and tensile bond strength of dentin bonding systems after $\mathrm{NaOCl}$ treatment," J Adhes Dent, vol. 1, no. 2, pp. 135-42, 1999.

[33] A. Erdemir, H. Ari, H. Güngüneş, and S. Belli, "Effect of medications for root canal treatment on bonding to root canal dentin," Journal of Endodontics, vol. 30, no. 2, pp. 113-116, 2004.

[34] M. Khoroushi and M. Kachuei, "Pull-out bond strength of a selfadhesive resin cement to $\mathrm{NaOCl}$-treated root dentin: effect of antioxidizing agents," Restorative Dentistry \& Endodontics, vol. 39, no. 2, pp. 95-103, 2014.

[35] D. Cecchin, A. P. Farina, D. Galafassi, J. V. B. Barbizam, S. A. M. Corona, and B. Carlini-Júnior, "Influence of sodium hypochlorite and EDTA on the microtensile bond strength of a self-etching adhesive system," Journal of Applied Oral Science, vol. 18, no. 4, pp. 385-389, 2010. 
[36] N. Uceda-Gomez, A. Reis, M. R. Carrilho, A. D. Loguercio, and L. E. Rodriguez Filho, "Effect of sodium hypochlorite on the bond strength of an adhesive system to superficial and deep dentin," Journal of Applied Oral Science, vol. 11, no. 3, pp. 223228, 2003.

[37] J. Perdigão, J. Y. Thompson, M. Toledano, and R. Osorio, "An ultra-morphological characterization of collagen-depleted etched dentin," American Journal of Dentistry, vol. 12, no. 5, pp. 250-255, 1999.

[38] M. Di Francescantonio, H. Nurrohman, T. Takagaki, T. Nikaido, J. Tagami, and M. Giannini, "Sodium hypochlorite effects on dentin bond strength and acid-base resistant zone formation by adhesive systems," Brazilian Journal of Oral Sciences, vol. 14, no. 4, pp. 334-340, 2015.

[39] C. H. Weston, S. Ito, B. Wadgaonkar, and D. H. Pashley, "Effects of Time and Concentration of Sodium Ascorbate on Reversal of NaOCl-Induced Reduction in Bond Strengths," Journal of Endodontics, vol. 33, no. 7, pp. 879-881, 2007.

[40] P. J. Stoward, "A histochemical study of the apparent deamination of proteins by sodium hypochlorite," Histochemistry, vol. 45, no. 3, pp. 213-226, 1975.

[41] C. L. Hawkins and M. J. Davies, "Hygochlorite-induced oxidation of proteins in plasma: Formation of chloramines and nitrogen-centred radicals and their role in protein fragmentation," Biochemical Journal, vol. 340, no. 2, pp. 539-548, 1999.

[42] S. E. M. Saber and F. S. El-Askary, "The outcome of immediate or delayed application of a single-step self-etch adhesive to coronal dentin following the application of different endodontic irrigants," Eur J Dent, vol. 3, pp. 83-89, 2009.

[43] H. Ari and A. Erdemir, "Effects of endodontic irrigation solutions on mineral content of root canal dentin using ICPAES technique," Journal of Endodontics, vol. 31, no. 3, pp. 187189, 2005.

[44] T. P. C. Sim, J. C. Knowles, Y.-L. Ng, J. Shelton, and K. Gulabivala, "Effect of sodium hypochlorite on mechanical properties of dentine and tooth surface strain," International Endodontic Journal, vol. 34, no. 2, pp. 120-132, 2001.

[45] M. Marending, H. U. Luder, T. J. Brunner, S. Knecht, W. J. Stark, and M. Zehnder, "Effect of sodium hypochlorite on human root dentine - Mechanical, chemical and structural evaluation," International Endodontic Journal, vol. 40, no. 10, pp. 786-793, 2007.

[46] T. Prasansuttiporn, M. Nakajima, S. Kunawarote, R. M. Foxton, and J. Tagami, "Effect of reducing agents on bond strength to NaOCl-treated dentin," Dental Materials, vol. 27, no. 3, pp. 229234, 2011.

[47] S. B. Berger, R. P. De Souza Carreira, R. D. Guiraldo et al., "Can green tea be used to reverse compromised bond strength after bleaching?" European Journal of Oral Sciences, vol. 121, no. 4, pp. 377-381, 2013.

[48] V. S. Manimaran, S. Srinivasulu, A. V. R. Ebenezar, S. Mahalaxmi, and N. Srinivasan, "Application of a proanthocyanidin agent to improve the bond strength of root dentin treated with sodium hypochlorite," Journal of Conservative Dentistry, vol. 14, no. 3, pp. 306-308, 2011.

[49] D. Shrestha, W.-C. Wu, Q.-Y. He, X. Wei, and J.-Q. Ling, "Effect of sodium ascorbate on degree of conversion and bond strength of RealSeal SE to sodium hypochlorite treated root dentin," Dental Materials Journal, vol. 32, no. 1, pp. 96-100, 2013.

[50] S. C. N. Lai, Y. F. Mak, G. S. P. Cheung et al., "Reversal of compromised bonding to oxidized etched dentin," Journal of Dental Research, vol. 80, no. 10, pp. 1919-1924, 2001.
[51] L. P. Gao, H. L. Wei, H. S. Zhao, S. Y. Xiao, and R.-L. Zheng, "Antiapoptotic and antioxidant effects of rosmarinic acid in astrocytes," Pharmazie, vol. 60, no. 1, pp. 62-65, 2005.

[52] O. Fadel, K. El Kirat, and S. Morandat, "The natural antioxidant rosmarinic acid spontaneously penetrates membranes to inhibit lipid peroxidation in situ," Biochimica et Biophysica Acta-Biomembranes, vol. 1808, no. 12, pp. 2973-2980, 2011.

[53] O. Akina, Y. Yoshitaka, D. Yoshiaki, and S. Kunniaki, "Rosmarinic acid and arbutin suppress osteoclast differentiation by inhibiting superoxide and NFATcl downregulation in RAW 264.7 cellsRosmarinic acid and arbutin suppress osteoclast differentiation by inhibiting superoxide and NFATc1 downregulation in RAW 264.7 cells," Biomedical Reports, vol. 3, no. 4, pp. 483-490, 2015.

[54] M. Demeule, M. Brossard, M. Pagé, D. Gingras, and R. Béliveau, "Matrix metalloproteinase inhibition by green tea catechins," Biochimica et Biophysica Acta-Protein Structure and Molecular Enzymology, vol. 1478, no. 1, pp. 51-60, 2000.

[55] M. Pujar, C. Patil, and A. Kadam, "Comparison of antimicrobial efficacy of Triphala, (GTP) Green tea polyphenols and 3\% of sodium hypochlorite on Enterococcus faecalis biofilms formed on tooth substrate: in vitroFormed on Tooth Substrate: An In Vitro Study," Journal of International Oral Health, vol. 3, no. 2, pp. 23-29, 2011.

[56] M. S. Sadr Lahijani, H. R. Raoof Kateb, R. Heady, and D. Yazdani, "The effect of German chamomile (Marticaria recutita L.) extract and tea tree (Melaleuca alternifolia L.) oil used as irrigants on removal of smear layer: A scanning electron microscopy study," International Endodontic Journal, vol. 39, no. 3, pp. 190-195, 2006.

[57] C. Carvalho, F. P. Fernandes, V. D. P. Freitas et al., "Effect of green tea extract on bonding durability of an etch-and-rinse adhesive system to caries-affected dentin," Journal of Applied Oral Science, vol. 24, no. 3, pp. 211-217, 2016.

[58] A. M. Fine, "Oligomeric proanthocyanidin complexes: History, structure, and phytopharmaceutical applications," Alternative Medicine Review, vol. 5, no. 2, pp. 144-151, 2000.

[59] M. Kalra, K. Iqbal, L. I. Nitisusanta, U. Daood, C. P. Sum, and A. S. Fawzy, "The effect of proanthocyanidins on the bond strength and durability of resin sealer to root dentine," International Endodontic Journal, vol. 46, no. 2, pp. 169-178, 2013.

[60] D. J. Epasinghe, C. K. Y. Yiu, M. F. Burrow, F. R. Tay, and N. M. King, "Effect of proanthocyanidin incorporation into dental adhesive resin on resin-dentine bond strength," Journal of Dentistry, vol. 40, no. 3, pp. 173-180, 2012.

[61] X. Y. Benjamin Hechler and Y. Wang, "Proanthocyanidins alter adhesive/dentin bonding strengths when included in a bonding system," American Journal of Dentistry, vol. 25, no. 5, pp. 276280, 2012. 

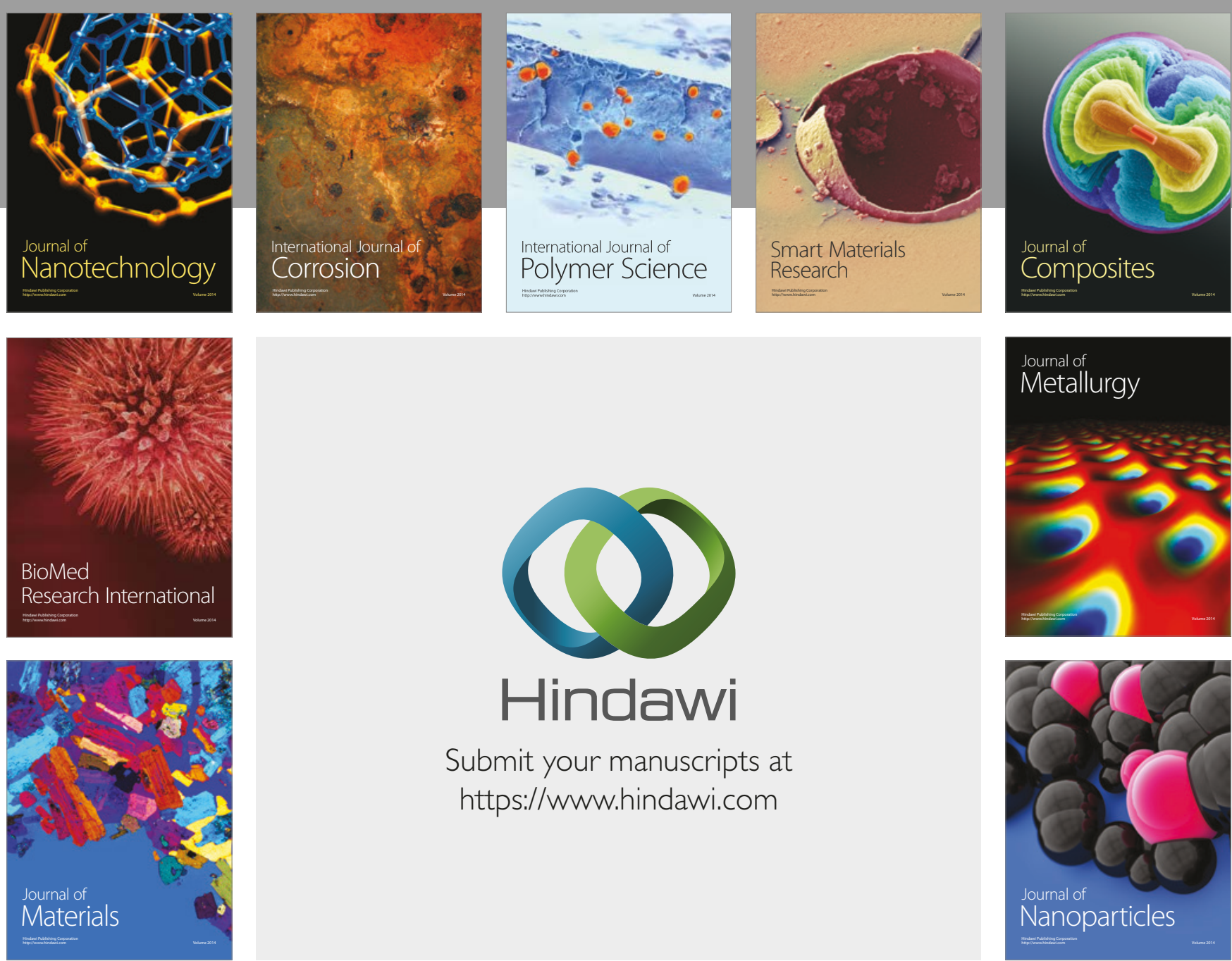

\section{Hindawi}

Submit your manuscripts at

https://www.hindawi.com
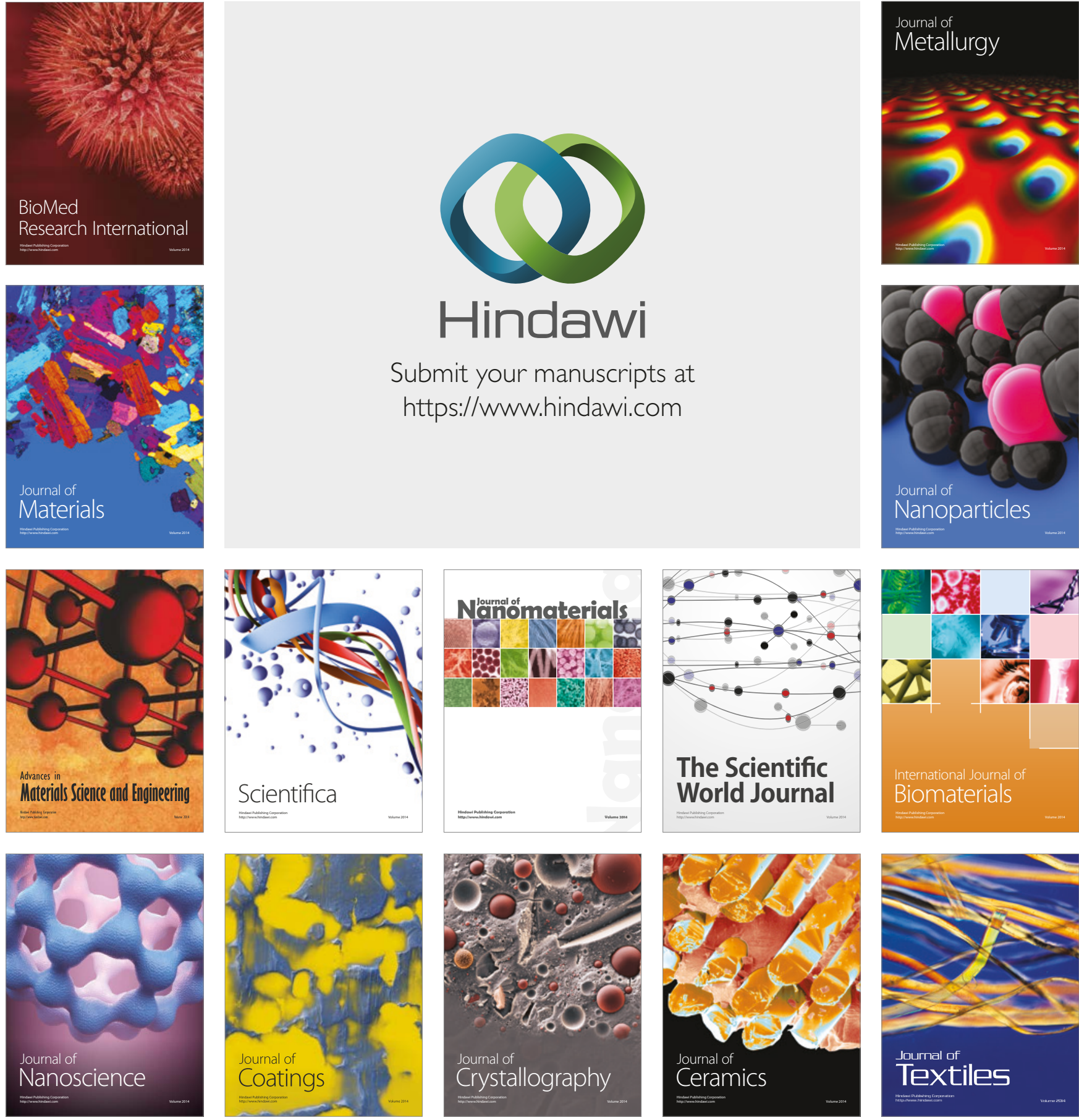

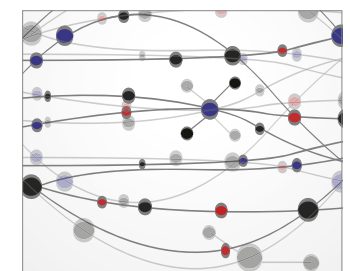

The Scientific World Journal
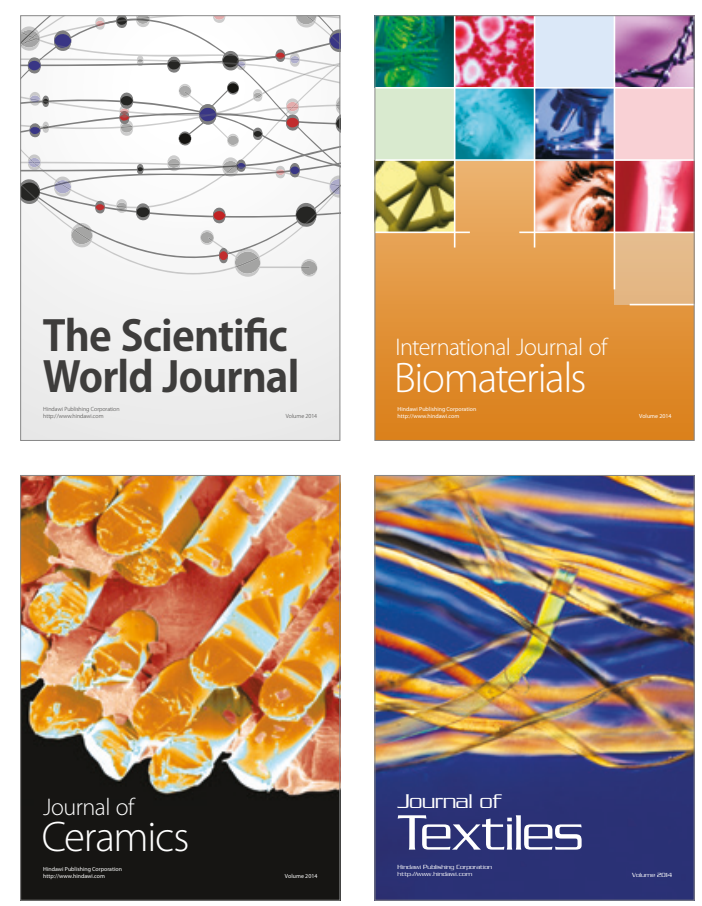